Material Properties

\title{
Synergistic effect by high specific surface area carbon black as secondary filler in silica reinforced natural rubber tire tread compounds
}

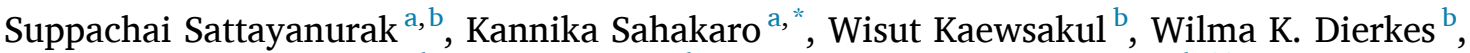 \\ Louis A.E.M. Reuvekamp ${ }^{\mathrm{b}, \mathrm{c}}$, Anke Blume ${ }^{\mathrm{b}}$, Jacques W.M. Noordermeer ${ }^{\mathrm{b}, * *}$ \\ ${ }^{a}$ Department of Rubber Technology and Polymer Science, Faculty of Science and Technology, Prince of Songkla University, Pattani Campus, 94000, Thailand \\ ${ }^{\mathrm{b}}$ Elastomer Technology and Engineering, Department of Mechanics of Solids, Surfaces and Systems, Faculty of Engineering Technology, University of Twente, P.O.Box \\ 217, 7500AE, Enschede, the Netherlands \\ ${ }^{\mathrm{c}}$ Apollo Tyres Global R\&D B.V, Colosseum 2, 7521PT, Enschede, the Netherlands
}

\section{A R T I C L E I N F O}

\section{Keywords:}

Silica

Carbon black

Natural rubber

Tire tread compound properties

\begin{abstract}
A B S T R A C T
The partial replacement of silica by high specific surface area and high structure Carbon Black (CB) N134 as secondary filler, keeping the same total filler content at $55 \mathrm{phr}$, shows a clear synergistic effect on overall performance. At low content of $\mathrm{CB}$, i.e. in the range of $0-36 \mathrm{wt} \%$ of $\mathrm{CB}$ relative to total filler amount, the Payne effect and tan delta at both $0{ }^{\circ} \mathrm{C}$ and $60^{\circ} \mathrm{C}$ change marginally, but thereafter gradually increase. Cure times are shortened in the presence of $\mathrm{CB}$, facilitating an increase of productivity. Bound rubber content and mechanical properties show an optimum at $18 \mathrm{wt} \%$ of CB relative to total filler amount or at a ratio of silica/CB 45/10 phr. With regard to tire performance as indicated by the laboratory test results, the abrasion resistance, wet grip and ice traction can therefore be enhanced while maintaining the tire rolling resistance at the optimum level for this silica/CB ratio.
\end{abstract}

\section{Introduction}

Natural rubber is widely used in all types of tires especially for heavy truck and aircraft tires in order to obtain a low heat build-up level and good mechanical strength. Moreover, many components of passenger car tires are also composed of NR such as bead filler, sidewall and tread compounds, making use of its low heat build-up, good flex-fatigue resistance as well as mechanical properties. Tires are built from several components that are made from different type of compounds which contain about $30 \%$ by weight of particulate reinforcing fillers such as carbon black and silica [1]. Carbon Black (CB) was the first reinforcing filler for rubber compounds to improve modulus, tensile and tear strength, abrasion resistance, skid resistance and other properties. The properties of the reinforced materials are influenced by the filler's particle size, surface area, structure and surface chemistry [2]. Replacement of CB with silica in passenger car tire tread compounds, after the patent of Michelin in 1992 [3], offers tire compounds with lower rolling resistance and higher wet grip [4], so less fuel consumption and better driving safety. However, the successful use of silica in rubber compounds requires sufficient bonding and/or interaction between the silica and elastomer interphases because of differences in polarity of silica and rubbers. The silica surface has a large number of silanol groups that are highly polar and can form hydrogen bonding with polar materials, especially amine-based accelerators causing an adsorption of the curing agents on the silica surface and retardation of the vulcanization reaction [5]. Moreover, these polar silanol groups cause strong filler-filler interactions and so it is difficult to disperse silica well in the non-polar tire rubbers and to obtain sufficient interfacial compatibility. However, these difficulties can be overcome by the use of silica in combination with silane coupling agents.

Mixing of silica with silane in rubber involves a chemical reaction, the so-called silanization [1,6] which takes place between the alkoxy groups of the silane and the silanol groups of the silica. The main governing parameter is the discharge mixing temperature [7,8], where the reaction can be catalyzed by the presence of diphenyl guanidine or alternative amines $[9,10]$. Sulfur containing silane coupling agents such as bis-(3-TriEthoxySilylPropyl)Tetrasulfide (TESPT) are commonly applied in such compounds vulcanized with a sulfur system, as TESPT

\footnotetext{
* Corresponding author.

$* *$ Corresponding author.

E-mail addresses: kannika.sah@psu.ac.th (K. Sahakaro), j.w.m.noordermeer@utwente.nl (J.W.M. Noordermeer).
} 
has the drawback of short scorch times due to free sulfur that is released during high temperature mixing by creating premature crosslink reactions [7], a silane with smaller sulfur rank such as bis-(3-TriEthoxySilylPropyl)Disulfide (TESPD) can be used and is applied in this present study.

Recently, a new generation of reinforcing fillers for rubber products have been introduced, especially nanofillers $[11,12]$ such as nanoclay, carbon nanotubes and graphene. There is a growing interest to use a filler combination or hybrid fillers making use of the benefits provided by the individual components. Silica has been used in combination with secondary fillers such as China clay [13], montmorillonite [14,15], kaolin [16], organically modified nanoclay [17] and CB [18-23] aiming for a synergistic effect on the rubber properties. The simplest combination should be silica/CB as both types of fillers are already commonly used in tire compounds. The use of a silica and carbon black combination in NR-based truck tread compounds was investigated before and the results indicated that when CB N220 was completely replaced by TESPT-modified silica, the rolling resistance was improved by about $30 \%$ while there was little change in the tread wear index (abrasion resistance) and wet traction [18]. An investigation of the influence of silica mixed with CB N220 in the presence and absence of a silane coupling agent on retraction behavior of NR vulcanizates [19] showed that the vulcanizates containing the silane coupling agent provided faster recovery rates compared to those without, due to the polymer-filler interactions, crosslinks between the rubber and silica, and increased crosslink densities. With increasing silica proportion in the silica/CB mixes, the vulcanizates with and without the silane coupling agent showed a decrease in hardness and modulus, but the ones with the silane coupling agent had higher values due to better filler dispersion and higher crosslink density than those without the silane coupling agent. A study on mechanical properties of NR reinforced with various ratios of CB N330/silica hybrid fillers showed that vulcanizates containing 20 and $30 \mathrm{phr}$ of silica in a total of mixed filler of $50 \mathrm{phr}$ exhibited the best overall mechanical properties [20]. The addition of a small amount of silica (VN3) into Solution-Styrene-Butadiene-Rubber (SSBR)/CB (N330) compounds, such as by the use of a $\mathrm{CB} /$ silica ratio of $45 / 5 \mathrm{phr}$, decreased the filler cluster branching and increased the reinforcement efficiency [21]. This decreased filler networking and more homogeneous filler dispersion subsequently resulted in better abrasion resistance, lower rolling resistance and better wet skid resistance, i.e. better dynamic properties. However, when the silica proportion was raised, filler cluster branching increased quickly and deteriorated the properties.

In addition to tire rubbers, the effect of $\mathrm{CB} /$ silica hybrid fillers in a polar rubber like acrylo-Nitrile-Butadiene-Rubber (NBR) has also been investigated [22]. The cure characteristics and physico-mechanical properties of NBR filled with Semi-Reinforcing Furnace (SRF) black (N770)/silica (Hisil233) were studied, in which the total filler content was kept constant at $50 \mathrm{phr}$ and the silica content was varied at $0,10,20$, $25,30,40$ and $50 \mathrm{phr}$. The cure time $\left(\mathrm{t}_{\mathrm{c} 90}\right)$, scorch time $\left(\mathrm{t}_{\mathrm{s} 2}\right)$, minimum torque $\left(\mathrm{M}_{\mathrm{L}}\right)$, and maximum torque $\left(\mathrm{M}_{\mathrm{H}}\right)$ of $\mathrm{CB}$ /silica-filled NBR compounds increased as the silica content was raised. The replacement of $\mathrm{CB}$ with silica decreased the material's stiffness, tensile strength, compressive strength, tear strength and modulus, but increased elongation at break and rebound resilience.

Although the use of CB in combination with silica has been widely studied and previously reported, the use of $\mathrm{CB}$ as secondary filler in silica-reinforced NR compounds aiming to enhance tire performance has not been considered. Our previous report on the effect of addition of small amounts of organoclay and $\mathrm{CB}$ as secondary fillers to silicareinforced natural rubber tire tread compounds [23] shows that the properties of compounds are affected by the mixing dump temperature. An increased dump temperature leads to a better silanization reaction between the silica and the coupling agent TESPD, but at too high mixing temperatures NR degradation can occur. The present study employs high specific surface area and structure CB N134 in synergy with silica in NR tire tread compounds. In the present work, the hybrid filler of silica/CB-filled NR with various ratios is investigated keeping the total filler content constant at $55 \mathrm{phr}$. The effect of CB N134 on the properties of silica-reinforced NR compounds is investigated with respect to filler networking, filler-filler interactions, filler-rubber interactions, cure characteristics, tensile properties, dynamic properties and abrasion resistance, all of importance for tire performance.

\section{Experimental}

\subsection{Materials}

Natural Rubber (Ribbed Smoked Sheet No.3, RSS3) was provided by Sri Trang Agro-Industry, Thailand. Silica ULTRASIL 7005 with a CTAB (cetyl-trimethyl-ammonium-bromide) and BET (Brunauer-EmmetTeller) specific surface area of 171 and $190 \mathrm{~m}^{2} / \mathrm{g}$, respectively, and silane coupling agent bis-(3-triethoxysilylpropyl)disulfide (TESPD) were obtained from Evonik, Germany. Carbon black (N134) with a CTAB and BET specific surface areas of 134 and $145 \mathrm{~m}^{2} / \mathrm{g}$, respectively, was provided by Phillips Carbon Black Limited, India. The other ingredients: Treated Distillate Aromatic Extract oil (TDAE oil) (Vivatec 500) (Hansen \& Rosenthal, Germany); diphenyl guanidine (DPG), N-cyclohexyl-2benzothiazyl sulfenamide (CBS), 2,2,4-trimethyl-1,2-dihydroquinoline (TMQ) (all from Flexys, Belgium); zinc oxide ( $\mathrm{ZnO}$ ), stearic acid and sulfur are commercial grades for the rubber industry.

\subsection{Preparation of rubber compounds}

The rubber compounds were prepared using a two-step mixing procedure following the formulation as shown in Table 1. The first step was to prepare a masterbatch of rubber and fillers, and the second one was to prepare the final compounds including the curatives. For the first step, an internal mixer Brabender Plasticorder $350 \mathrm{ml}$ was used and the mixing conditions were at a rotor speed of $60 \mathrm{rpm}$, fill factor of $70 \%$ and initial mixer temperature setting of $100^{\circ} \mathrm{C}$. The CB N134 was added together with the first half of silica, TESPD and DPG secondary accelerator. The other halves of silica and TESPD were added later on in the first mixing step, together with treated distillate aromatic extract (TDAE) extender oil. The CB amounts were varied at 0, 5, 10, 20, 30, 40, 50 and $55 \mathrm{phr}$ or $0,9,18,36,55,73,91$ and $100 \mathrm{wt} \%$ relative to total filler content. The second step involved the addition of the second half of DPG, CBS and sulfur at a rotor speed of $30 \mathrm{rpm}$, fill factor of $70 \%$, and an initial temperature setting of the internal mixer of $70^{\circ} \mathrm{C}$. The two-step mixing procedure is summarized in Scheme 1.

\subsection{Mooney viscosity}

Mooney viscosity, ML(1 + 4) $100{ }^{\circ} \mathrm{C}$ was tested using a Mooney viscometer (MV2000VS, Alpha Technologies, Akron, USA) according to ASTM D1646.

\subsection{Bound rubber content (BRC)}

An amount of $0.25 \mathrm{~g}$ of uncured compound (without curatives) was immersed in $40 \mathrm{ml}$ of toluene for 7 days at room temperature in a normal or an ammonia atmosphere. The ammonia atmosphere was used in order to cleave the physical linkages between silica and rubber but leave the chemical links intact. Then the sample was removed from the toluene, dried at $80^{\circ} \mathrm{C}$ in a vacuum oven for $24 \mathrm{~h}$ and weighed. The bound rubber content (BRC) was calculated using the following equation.

$\operatorname{BRC}(\%)=\frac{\left(m-m_{s}\right)}{m_{r}} \times 100$

where $m$ is the weight of sample after extraction, $m_{s}$ and $m_{r}$ are the weights of filler and rubber in the original sample, respectively. Normal 
Table 1

Formulations of silica-filled NR compounds with carbon black as a secondary filler.

\begin{tabular}{|c|c|c|c|c|c|c|c|c|}
\hline \multirow[t]{2}{*}{ Ingredients } & \multicolumn{8}{|c|}{ Amount (phr) } \\
\hline & Reference & 1 & 2 & 3 & 4 & 5 & 6 & 7 \\
\hline RSS3 & 100.0 & 100.0 & 100.0 & 100.0 & 100.0 & 100.0 & 100.0 & 100.0 \\
\hline ULTRASIL7005 & 55.0 & 50.0 & 45.0 & 35.0 & 25.0 & 15.0 & 5.0 & - \\
\hline CB N134 & - & 5.0 & 10.0 & 20.0 & 30.0 & 40.0 & 50.0 & 55.0 \\
\hline TESPD $^{\mathrm{a}}$ & 5.0 & 4.5 & 4.1 & 3.2 & 2.3 & 1.4 & 0.5 & - \\
\hline TDAE oil & 8.0 & 8.0 & 8.0 & 8.0 & 8.0 & 8.0 & 8.0 & 8.0 \\
\hline $\mathrm{ZnO}$ & 3.0 & 3.0 & 3.0 & 3.0 & 3.0 & 3.0 & 3.0 & 3.0 \\
\hline Stearic acid & 1.0 & 1.0 & 1.0 & 1.0 & 1.0 & 1.0 & 1.0 & 1.0 \\
\hline TMQ & 1.0 & 1.0 & 1.0 & 1.0 & 1.0 & 1.0 & 1.0 & 1.0 \\
\hline $\mathrm{DPG}^{\mathrm{a}}$ & 1.1 & 1.0 & 0.9 & 0.7 & 0.5 & 0.3 & 0.1 & - \\
\hline CBS & 1.5 & 1.5 & 1.5 & 1.5 & 1.5 & 1.5 & 1.5 & 1.5 \\
\hline Sulfur & 1.5 & 1.5 & 1.5 & 1.5 & 1.5 & 1.5 & 1.5 & 1.5 \\
\hline $\mathrm{CB}$ amounts in wt $\%$ relative to total fillers ${ }^{\mathrm{b}}$ & 0 & 9 & 18 & 36 & 55 & 73 & 91 & 100 \\
\hline
\end{tabular}

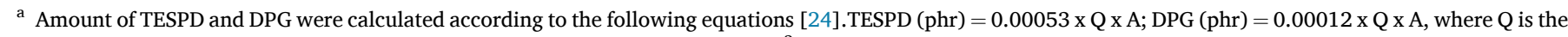
amount of silica (phr) and A is the CTAB specific surface area of the silica $\left(171 \mathrm{~m}^{2} / \mathrm{g}\right)$.

b Designation of the compounds: CB-0\%, CB-9\%, CB-18\%, CB-36\%, CB-55\%, CB-73\%, CB-91\% and CB-100\%.

\section{Masterbatch mixing stage}

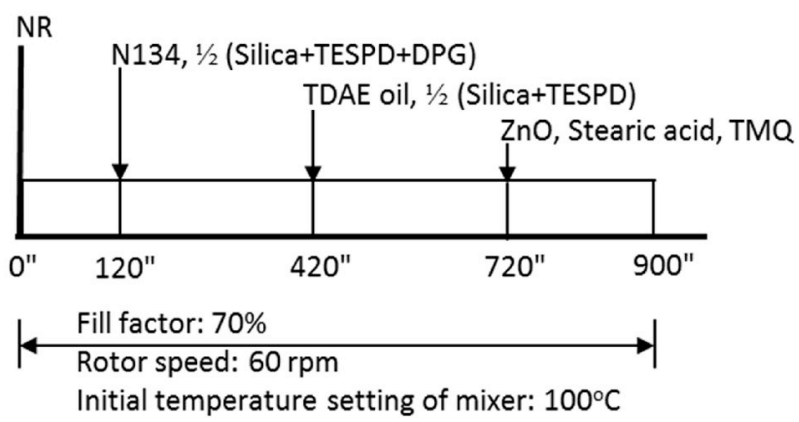

Final mixing stage

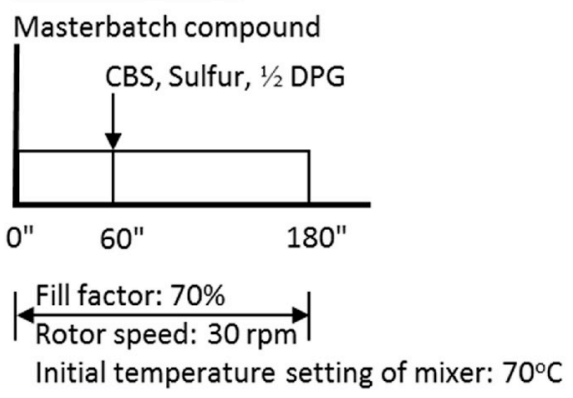

Scheme 1. Two-step mixing procedure for compound preparation.

atmosphere corresponds to Total Bound Rubber Content; ammonia atmosphere to Chemically Bound Rubber Content.

\subsection{Payne effect}

The storage shear moduli $\left(\mathrm{G}^{\prime}\right)$ of the rubber compounds with curatives was evaluated by using an RPA 2000 (Alpha Technologies) at a temperature of $100^{\circ} \mathrm{C}$, frequency of $0.5 \mathrm{~Hz}$ and varying strains in the range of $0.56-100 \%$. The Payne effect was taken as the difference in storage shear moduli at low strain $(0.56 \%)$ and high strain $(100 \%)$.

\subsection{Flocculation rate constant $\left(k_{a}\right)$}

The flocculation rate constant $\left(k_{a}\right)$ of the uncured silica-reinforced NR compounds with curatives was studied using the RPA at $100^{\circ} \mathrm{C}$, strain $0.56 \%$, frequency $1.00 \mathrm{~Hz}$, and test time of $12 \mathrm{~min}$. The storage shear moduli at different times were measured and the $k_{a}$ was calculated following Equations (2) and (3):

$x=\frac{G^{\prime}(t)-G^{\prime}(1)}{G^{\prime}(\infty)-G^{\prime}(1)}$

where $x$ is the degree of flocculation, $\mathrm{G}^{\prime}(\mathrm{t})$ is the storage modulus at test time $t, G^{\prime}(1)$ is the storage modulus after heating for $1 \mathrm{~min}$ and $\mathrm{G}^{\prime}(\infty)$ is the storage modulus after heating for $12 \mathrm{~min}$.

$k_{a}=\frac{\ln \left(1-x_{1}\right)-\ln \left(1-x_{2}\right)}{t_{2}-t_{1}}$

where $\mathrm{x}_{1}$ and $\mathrm{x}_{2}$ are the degree of flocculation at different heating times, i.e. $t_{1}$ and $t_{2}$, respectively.

\subsection{Cure characteristics}

Scorch time $\left(\mathrm{t}_{\mathrm{s} 2}\right)$, optimum cure time $\left(\mathrm{t}_{\mathrm{c} 90}\right)$ and cure rate index (CRI) were measured by using the RPA at $150{ }^{\circ} \mathrm{C}$, frequency $0.833 \mathrm{~Hz}$ and $2.79 \%$ strain for $30 \mathrm{~min}$. The CRI was calculated to equal [100/(optimum cure time - scorch time)].

\subsection{Tensile and tear properties}

The compounds were vulcanized to their optimum cure time $\left(\mathrm{t}_{\mathrm{c} 90}\right)$ by using a Wickert WLP 1600 laboratory compression press at $150{ }^{\circ} \mathrm{C}$ and 100 bars into $2 \mathrm{~mm}$ thick sheets. For tensile properties, Type 2 dumb-bell test specimens were die-cut from the press-cured sheets and tests were carried out with a Zwick tensile tester Model Z1.0/TH1S (Zwick Roell Group, Ulm, Germany) at a crosshead speed of $500 \mathrm{~mm} / \mathrm{min}$ according to ASTM D412. For tear strength, the vulcanized rubber was tested at room temperature using Delft-type specimens with the same machine and crosshead speed as applied for tensile tests according to ISO 34-2.

\subsection{DIN abrasion index and its abraded surface}

DIN abrasion index (ARI) was tested using a DIN abrader (Abrasion tester 564C, Karl Frank GmbH, Germany) according to method A of DIN 53516. The test specimen has a diameter of $16 \pm 2 \mathrm{~mm}$ with a minimum thickness of $6 \mathrm{~mm}$. The pure silica-filled NR was used as reference rubber. The ARI was calculated according to the following equation:

$A R I=\left(\frac{\Delta m_{r} \cdot d_{t}}{\Delta m_{t} \cdot d_{r}}\right) \cdot 100$

where $\Delta m_{r}$ is mass loss of the reference rubber $(\mathrm{g}), d_{r}$ is density of the reference rubber $\left(\mathrm{g} / \mathrm{cm}^{3}\right), \Delta m_{t}$ is mass loss of the test rubber $(\mathrm{g})$, and $d_{t}$ is density of the test rubber $\left(\mathrm{g} / \mathrm{cm}^{3}\right)$. 
The DIN abraded surface was characterized by scanning electron microscopy (SEM, Quanta 400, FEI Company, the Netherlands). The surface was coated with gold prior to being analyzed.

\subsection{Loss tangent or tan delta at $60^{\circ} \mathrm{C}$ by $R P A$}

The tan delta of the vulcanizates was determined using the RPA at $60{ }^{\circ} \mathrm{C}$ and strain $3.49 \%$ with varying frequencies in the range of $0.05-33.00 \mathrm{~Hz}$. The samples were first cured in the RPA chamber at $150{ }^{\circ} \mathrm{C}$ to their respective optimum cure times, before being tested.

\subsection{Tan delta at $-20^{\circ} \mathrm{C}, 0^{\circ} \mathrm{C}$ and $60^{\circ} \mathrm{C}$ by $D M A$}

Dynamic mechanical properties of the rubber vulcanizates were characterized in tension mode by using a Metravib Viscoanalyzer VA 2000 under a temperature sweep from $-80^{\circ} \mathrm{C}$ to $80^{\circ} \mathrm{C}$ at a frequency of $10 \mathrm{~Hz}$ and $0.1 \%$ strain. The sample dimension was $6 \times 4 \times 2 \mathrm{~mm}^{3}$. Tan delta at $-20^{\circ} \mathrm{C}$ and $0{ }^{\circ} \mathrm{C}$ were taken as indicative for ice traction and wet grip, respectively, and tan delta at $60^{\circ} \mathrm{C}$ to indicate tire rolling resistance of tire treads.

\section{Results and discussion}

\subsection{Mixing behavior, processability and cure properties}

The mixing footprints, showing both mixing torques and temperatures curves, of the silica/CB-filled NR compounds with various contents of CB N134 are presented in comparison with silica-filled NR are shown in Fig. 1.

The changes of mixing torque, indicative for viscosity, with mixing time depend on the types and ratio of silica/CB that were incorporated into the rubber matrix. The mastication of NR first decreases the torque due to a breakdown of high molecular weight rubber components under shearing force. Then the addition of solid fillers raises the torque or viscosity according to the hydrodynamic effect $[12,25]$. The addition of the second half of the fillers further increases the torques, while the addition of $\mathrm{ZnO}$, stearic acid and TMQ at the later stage results in a decrease of torque due to stearic acid that also acts as processing aid. Lateron, filler incorporation and dispersion result in a viscosity decrease. The pure silica-filled rubber compound shows the lowest mixing torque, while the inclusion of $\mathrm{CB}$ increases the torques and the pure CB-filled compound displays the highest torque. The changes of the final torques with the amount of $\mathrm{CB}$ are shown in Fig. 2(a) together with their respective discharge or dump temperatures.

The incorporation of high specific surface area and high structure CB N134 that has better compatibility with NR compared to polar silica, causes an increased interfacial contact and consequently higher viscosity of the masterbatch. The higher viscosity creates more shearing heat during mixing, as reflected in the continuous increase of the dump temperature with increasing the ratio of $\mathrm{CB}$ in the hybrid fillers. For the pure silica-filled compound with the use of TESPD silane coupling agent, the lowest dump temperature is observed corresponding to its lowest dump torque. The latter is in accordance with the Mooney viscosity and minimum cure torques $\left(\mathrm{M}_{\mathrm{L}}\right)$ as shown in Fig. 2(b). An interesting trend in the compound viscosities with the change of silica/CB ratio can be noticed; the viscosity rises sharply when $\mathrm{CB}$ is added in the range of 5-10 phr, i.e. 9-18 wt $\%$ relative to total filler, thereafter slightly decreases before an abrupt increase again when the CB content exceeds $50 \mathrm{wt} \%$. This phenomenon may be related to filler networking. The silanized silica has less filler networking after the silanization reaction, but the addition of a small amount of high structure CB may lead to a silica-CB filler network formation. However, once the $\mathrm{CB}$ amount is high enough in the mixture with silica and the viscosity is increased enough to create higher shearing forces, the filler network is reduced to balance the rise in viscosity. But due to the high specific surface area of $\mathrm{CB}$ and high fillerrubber interaction, the compounds that contain more $\mathrm{CB}$ than silica show again a rapid increase in viscosity. This is also due to the filler network of CB. Moreover, it is well established that the dump temperature is a key parameter affecting the silanization reaction for silicasilane compounds $[7,8,23]$. The higher dump temperature promotes a greater extent of the silanization and filler-rubber interactions and thus increases the viscosity. There is a slightly different trend in the change of viscosities in the compounds with high content of $\mathrm{CB}$, as determined by Mooney viscosity versus minimum cure torque and mixing torque. The higher temperature during cure measurement (at $150^{\circ} \mathrm{C}$ ) and during mixing promotes the mobility of both fillers and polymer chains and then facilitates filler flocculation [26-28] which also has an influence on the viscosity. So, as a whole this is a complex phenomenon which involves several parameters that can either increase or decrease the compound viscosity.

The addition of CB in combination with silica into the NR compounds affects the cure properties, i.e. scorch time $\left(t_{s 2}\right)$, cure time $\left(t_{c 90}\right)$ and cure

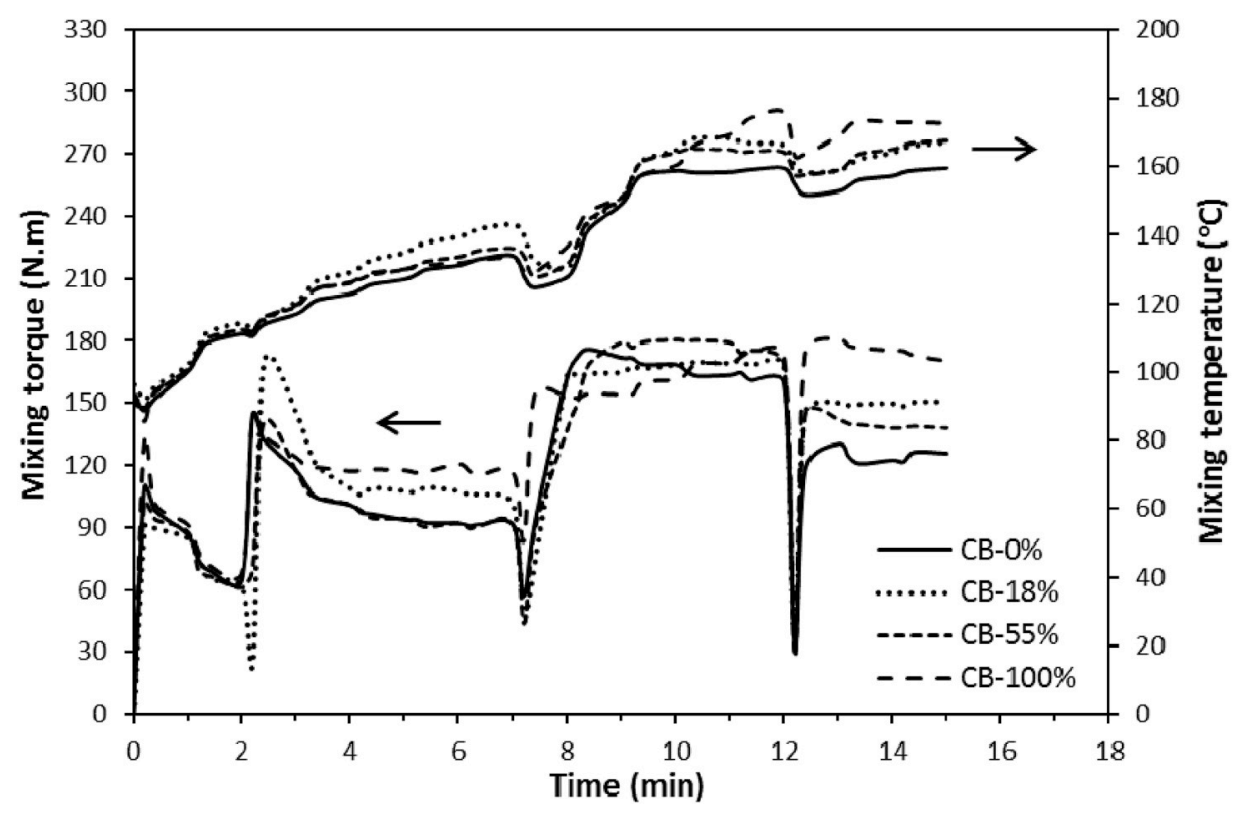

Fig. 1. Masterbatch mixing profiles of silica/CB-filled NR compounds with various contents of CB N134. 

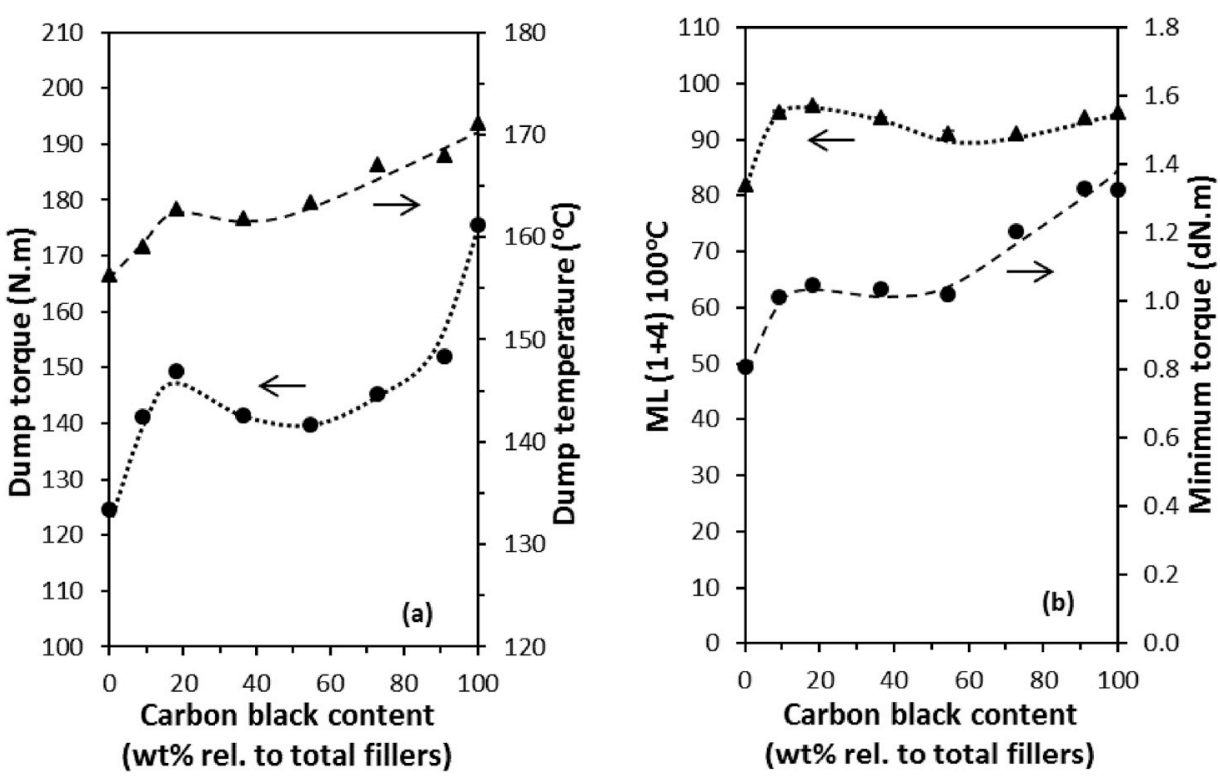

Fig. 2. Effect of CB N134 contents on dump torque and dump temperature (a) and Mooney viscosity and minimum torques (b) of silica/CB-filled NR compounds.

rate index (CRI), as displayed in Fig. 3. The polar silanol groups on the silica surface are known to have a negative effect on the vulcanization caused by accelerator adsorption and the acidic nature of silica [5]. Even though a silane coupling agent is used and the silanization reaction is optimized by controlling the dump temperature, it has been reported earlier based on model compound studies that only approximately $25 \%$ of the silanol groups on the silica can react with silanes due to limited accessibility of these silanol groups for incoming silane molecules [29]. The presence of small molecules like amine-based substance such as aliphatic amines and DPG in this work has been reported to help shielding off those left-over silanol groups and reduce the cure retardation $[9,10]$. Nevertheless, the pure silica-filled compound still shows longer scorch and cure times with lower cure rate index compared to the systems with silica/CB mixed fillers as corresponded to the previous works for silica/CB [23,30], silica/bentonite [31] and silica/nanoclay $[14,23]$. The addition of $\mathrm{CB}$ reduces both scorch and cure times

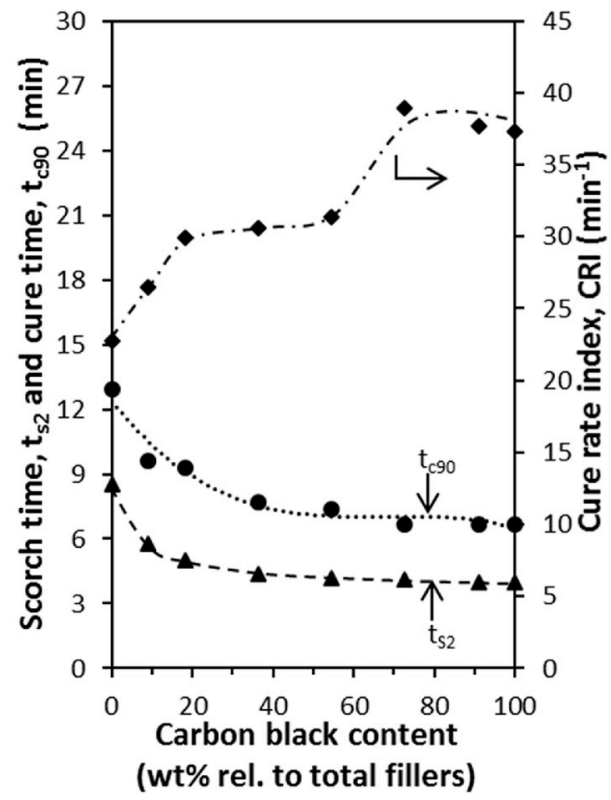

Fig. 3. Effect of CB N134 contents on scorch time and cure time (a) and cure rate index (b) of silica/CB-filled NR compounds. especially in the range of $0-40 \mathrm{wt} \%$ relative to total filler, thereafter the values decrease slightly with increasing amount of $\mathrm{CB}$. The addition of $\mathrm{CB}$ into the compounds raises the mixing temperature (Figs. 1 and 2(a)) that promotes the silanization, so there should be less free silanol groups left in such compounds. Moreover, as the thermal conductivity of carbon black is higher than for silica and the addition of $\mathrm{CB}$ particles into the rubber increases therefore the thermal conductivity [32,33], so by increasing the ratio of $\mathrm{CB}$ in the silica/CB-filled compounds, the vulcanization rate is enhanced. Thus, from the perspective of industrial processing, this increased cure rate is beneficial as it can promote the productivity and saves energy in the production of rubber products.

\subsection{Filler-filler interaction, filler-rubber interaction and flocculation}

Filler-filler and filler-elastomer interactions are important parameters that affect the reinforcement in elastomers. To determine the level of filler-filler interactions, a change of storage modulus with strain is normally measured as Payne effect, and expressed by the difference between storage moduli at low and high strains [34]. A larger difference, i.e. higher Payne effect, means a higher degree of filler-filler interactions. The results in Fig. 4 show that the Payne effect of silica/CB-filled NR compounds increases in the presence of CB N134. The use of $\mathrm{CB}$ at $18 \mathrm{wt} \%$ relative to total filler or at $10 \mathrm{phr}$ still keeps the Payne effect similar to that of the reference pure silica-filled compound. At low amount of CB below approximately $50 \mathrm{wt} \%$ of $\mathrm{CB}$ relative to total filler, the Payne effect tends to increase slightly, but there is a sharp rise at higher amounts indicating a large increase in filler network formation. The small particle size and high surface area of CB N134 with narrow filler particle-particle distances favor filler network formation and thus increase the Payne effect. In addition to the characteristics of N134 itself, based on the mixing temperatures shown in Figs. 1 and 2(a), the increasing temperature at higher loading of CB causes a lower viscosity of the compounds during mixing and this can also have an effect on the shearing force applied on the filler agglomerates during the dispersion process. The in situ low viscosity during the mixing generates less shearing forces to break down the filler agglomerates/aggregates as well as facilitates particle flocculation. So, the final compounds show high viscosity as well as high filler-filler interaction.

Bound rubber content was measured based on mass of rubber that is tightly adhered to the filler surface by both physical and chemical interactions and could not be dissolved by a good solvent anymore, i.e. toluene for NR. Chemically bound rubber content is widely accepted and 

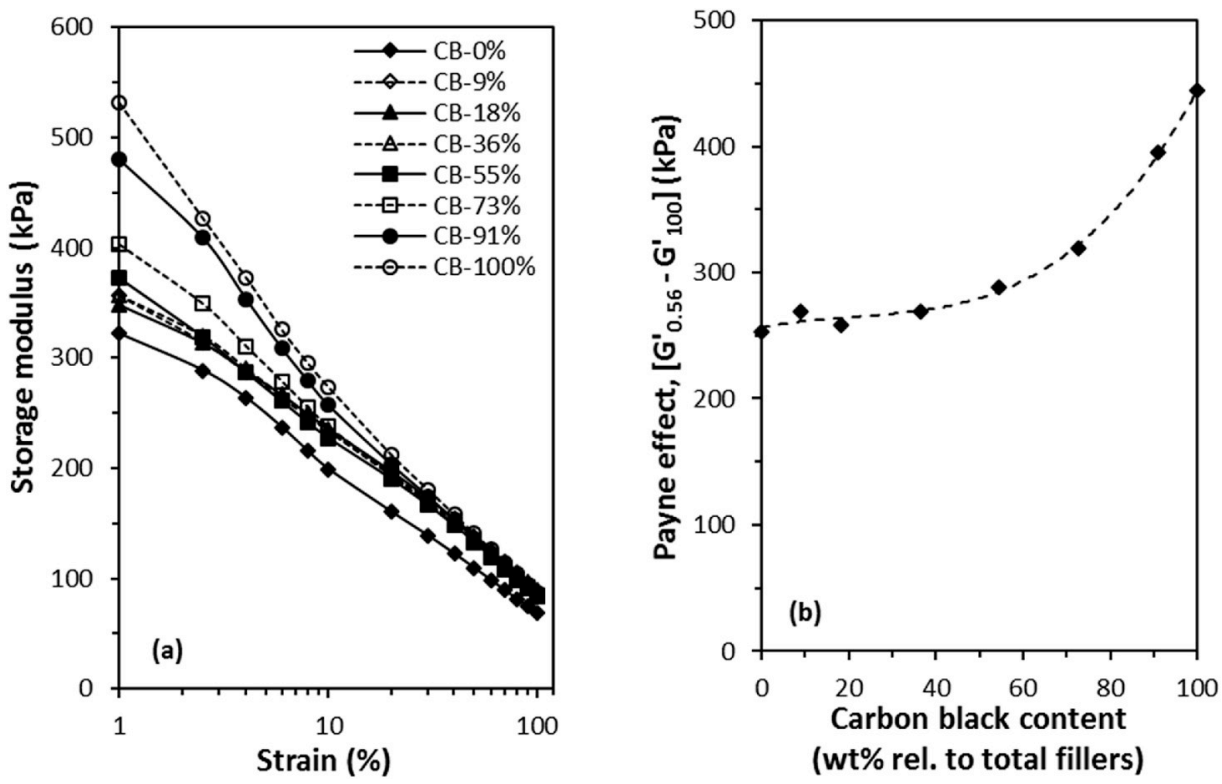

Fig. 4. Effect of CB N134 contents on storage modulus as a function of strain (a) and Payne effect (b) of silica/CB-filled NR compounds.

used to indicate filler-elastomer interactions [35-37]. The results in Fig. 5(a) show that the silica/CB-filled rubber compounds at every filler ratio have higher bound rubber contents than the mix with silica only, indicating their higher filler-elastomer interaction, derived from factors as more specific surface area of N134, better CB-rubber compatibility, higher extent of the silica-silanization due to a higher mixing temperature, more filler network and consequently more trapped or occluded rubber. Both the total bound rubber and chemically bound rubber contents of silica/CB-filled NR compounds show an optimum at CB content of $18 \mathrm{wt} \%$ relative to the total filler amount or at the ratio of silica/CB 45/10 phr. Thereafter, the values decrease and tend to stabilize with increasing CB content. The change of Mooney viscosity in Fig. 2 (b) corresponds well with this bound rubber content, mutually confirming each other.

The flocculation rate constants of silica/CB-filled NR compounds as shown in Fig. 5 (b) display an optimum point, i.e. the lowest flocculation rate constant, also at $18 \mathrm{wt} \%$ of $\mathrm{CB}$ relative to total filler amount, the

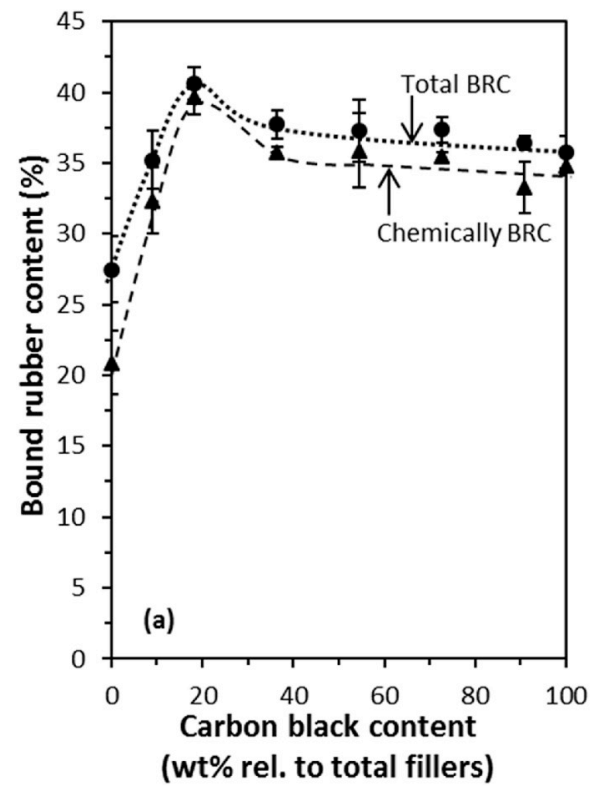

same ratio as observed for bound rubber content. A further increase of $\mathrm{CB}$ content rises the flocculation rate constant, in agreement with the increased Payne effect (Fig. 4(b)) and compound viscosity (Fig. 2(b). The sharp increase in viscosity and bound rubber content or fillerelastomer interaction when a small amount of high structure $\mathrm{CB}$ is added results in a restriction in filler mobility and therefore less flocculation. But once the concentration of $\mathrm{CB}$ is high, its small particle size and high surface area do actually facilitate filler network development by flocculation. The $\mathrm{CB}$ networking phenomenon is well recognized in previous reports $[26,38,39]$.

\subsection{Mechanical properties}

The increasing CB proportion in silica/CB-filled NR compounds has only a minor influence on the $100 \%$ modulus, but significantly raises the $300 \%$ modulus and reinforcement index, as shown in Fig. 6 (a). For carbon black reinforcement of elastomers, Fukahori [40] discussed that

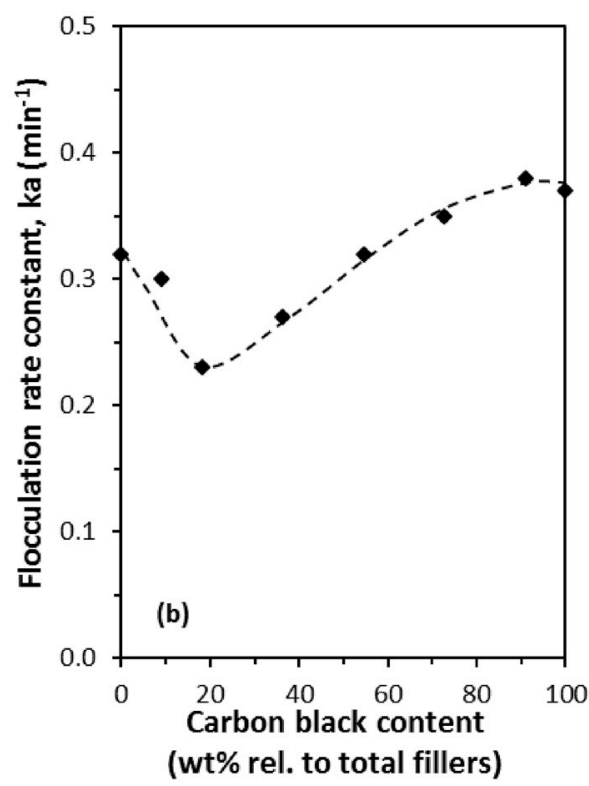

Fig. 5. Effect of CB N134 contents on total and chemically bound rubber contents (a) and flocculation rate constant (b) of silica/CB-filled NR compounds. 
a large stress increase with filler content and increasing strain amplitude results from a strong stress concentration generated around carbon black particles and its transmission to the whole system. The model proposed showed double uncrosslinked polymer layers of different molecular mobility; an inner glassy hard (GH) layer and an outer sticky less hard (SH) layer, surrounding a carbon particle. Under large extensions where a stress-hardened superstructure is produced in the SH layer, a great increase in tensile stress is observed. This corresponds with the observation in the present work, that the increase of $\mathrm{CB}$ content leads to a large rise in modulus at large extension, i.e. at $300 \%$. Moreover, as shown previously, the increase of $\mathrm{CB}$ content increases filler-filler and filler-rubber interactions that contribute to the stiffness of the materials.

Tensile strength and elongation at break of NR filled with silica in combination with various contents of $\mathrm{CB}$ show the same trend, as displayed in Fig. 6 (b), and resemble the change of bound rubber content in Fig. 5(a). Both properties initially increase when CB is added, but later decrease slightly after the $\mathrm{CB}$ content exceeds $18 \mathrm{wt} \%$ relative to total filler amount. When compared to the pure silica-filled compound, there is a smaller change in the tensile strength when the CB content is increased, but the elongation at break tends to drop at high amount of $\mathrm{CB}$, in line with the increase of modulus as shown in Fig. 6 (a).

The use of silica/CB hybrid filler further shows a clear improvement in tear strength and DIN abrasion index compared to the pure silicareinforced system as shown in Fig. 7. By increasing the content of CB, tear strength of the silica/CB-filled NR rises sharply to reach the maximum at $18 \mathrm{wt} \%$ of $\mathrm{CB}$ relative to total filler amount, then decreases slightly and stabilizes at the level higher than the reference compound. The changes of tear and tensile strength with the carbon black content therefore show a similar trend and correspond to the bound rubber content, indicating that the increase of filler-elastomer interactions does enhance the strength of the rubber vulcanizates. This increase in strength will benefit for truck tires performance, as crack growth and cut-chip resistance are related to tear strength are important properties for their application.

As expected, the addition of Super Abrasion Furnace (SAF) black N134 into the silica-reinforced NR compound does enhance the abrasion resistance, indicated by the increased DIN abrasion index as shown in Fig. 7. This is due to the higher surface area of $C B$, which imparts improved abrasion resistance to rubber vulcanizates in general. The results correspond to the increase of modulus as seen in Fig. 6(b), where

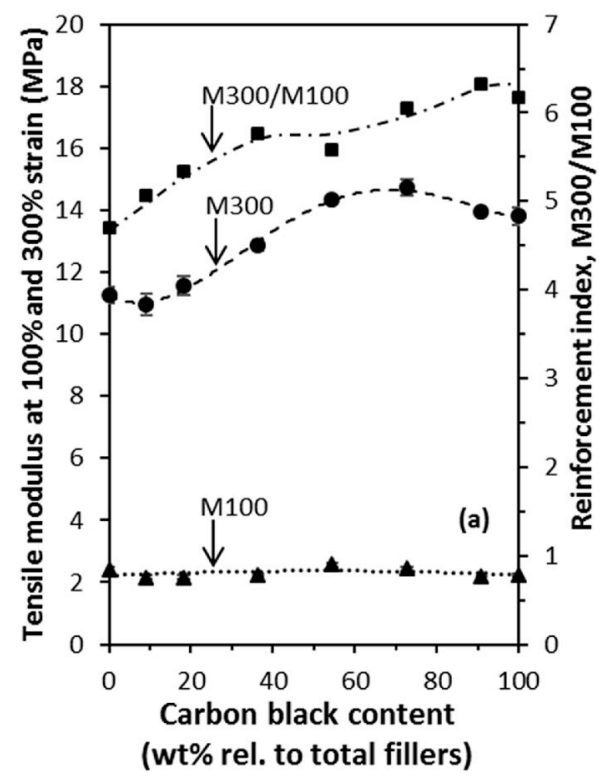

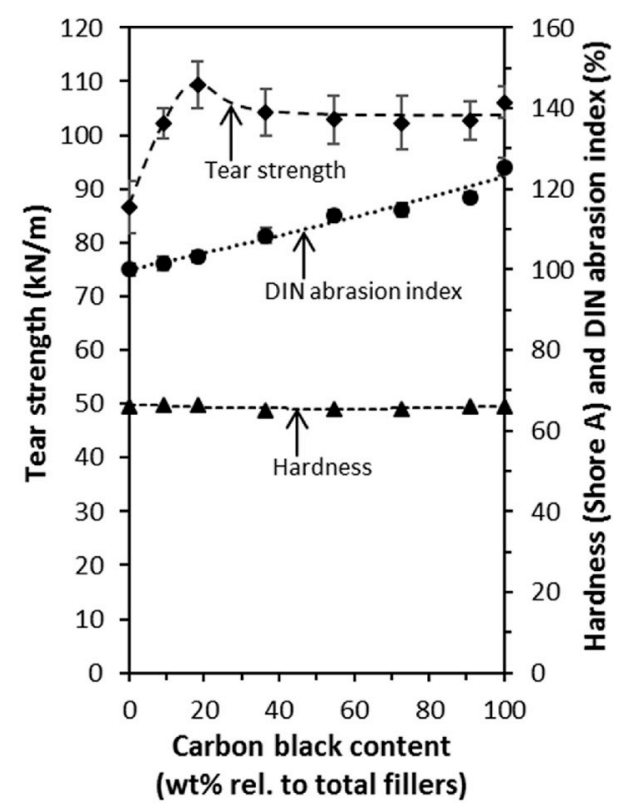

Fig. 7. Effect of CB N134 contents on tear strength and DIN abrasion index of silica/CB-filled NR compounds.

it has been reported that rubber vulcanizates with higher modulus show better abrasion resistance [20].

\subsection{SEM images of DIN abraded surfaces}

The wear of rubber products remains difficult to predict [41] and abrasion resistance of specimens tested in a laboratory often do not agree with the wear of the articles during service. Tearing or fatigue under the action of high local stresses caused by friction have been blamed as the main causes of abrasion [41]. When rubber is abraded without change of direction, an "Abrasion pattern" or sets of parallel ridges appear on the surface of the samples at right angles to the direction of motion, often called Schallamach waves [42,43] and this abrasion pattern is assumed to influence the relative rates of tire wear under different service conditions. These periodic parallel ridges or

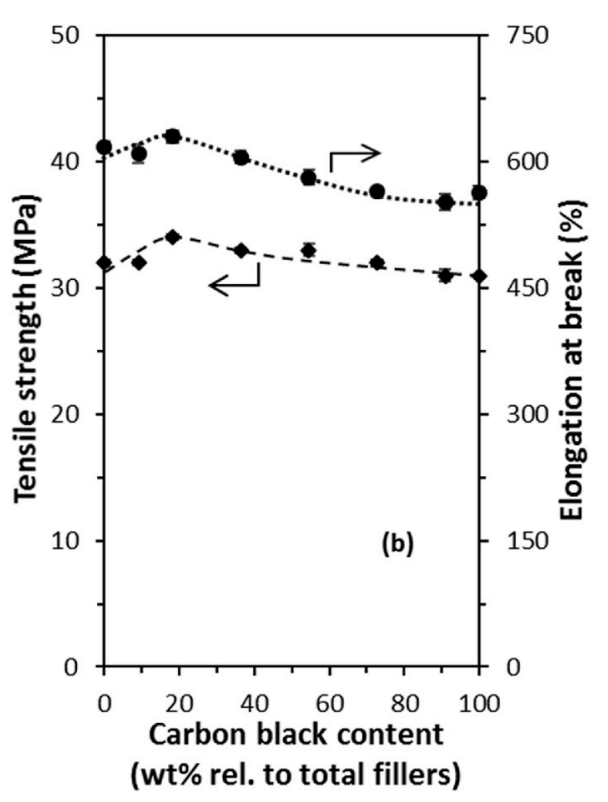

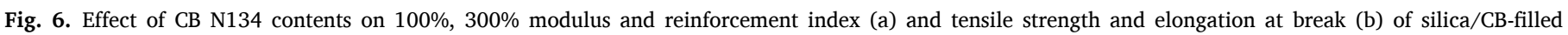
NR compounds. 
abrasion patterns are initiated by microvibrations at the natural frequency of the rubber and propagate by stick-slip oscillations, both of which are generated during frictional sliding of rubber [44]. The abrasion patterns of silica/CB-filled vulcanizates look different from that of pure silica-filled rubber as shown in Fig. 8. At higher content of $\mathrm{CB}$, the parallel ridges are more visible as the ridge spacings become smaller and ridge heights are larger. The increasing ratio of $\mathrm{CB}$ in the hybrid filler-reinforced NR increased the $300 \%$ modulus and tear strength, making the asperities more difficult to be torn off. On the other hand, due to the high natural strength of NR, it was reported that its DIN abrasion index is relatively insensitive to the black loading [41]. The results in Fig. 7 do show that by replacing silica with CB, the DIN abrasion index increases by around $20 \%$.

\subsection{Dynamic mechanical properties as indicative for tire performance}

In a laboratory scale test, dynamic mechanical analysis is commonly employed to predict tire performance with regard to wet grip and rolling resistance; tan delta at $-20{ }^{\circ} \mathrm{C}$ to $+20{ }^{\circ} \mathrm{C}$ is used to predict the wet traction of a tire while the tan delta at $60^{\circ} \mathrm{C}$ of vulcanizates indicates the loss energy of a rubber vulcanizate under dynamic deformation which relates to tire rolling resistance [45]. Fig. 9(a) shows the tan delta at $60{ }^{\circ} \mathrm{C}$ of silica/CB-filled compounds at various $\mathrm{CB}$ content from both RPA and DMA measurements. The tan delta values at $60^{\circ} \mathrm{C}$ remains at similar levels as that of pure silica-reinforced NR compounds when the $\mathrm{CB}$ content is in the range of $0-20 \mathrm{wt} \%$ relative to total filler content (based on the RPA results), or $0-50 \mathrm{wt} \%$ relative to total filler content (based on DMA results), thereafter a sharp increase is observed. The lowest tan delta at $60^{\circ} \mathrm{C}$ is observed for $\mathrm{CB}$ loading of $18 \mathrm{wt} \%$ relative to total filler content. With increasing the CB N134 content, the available
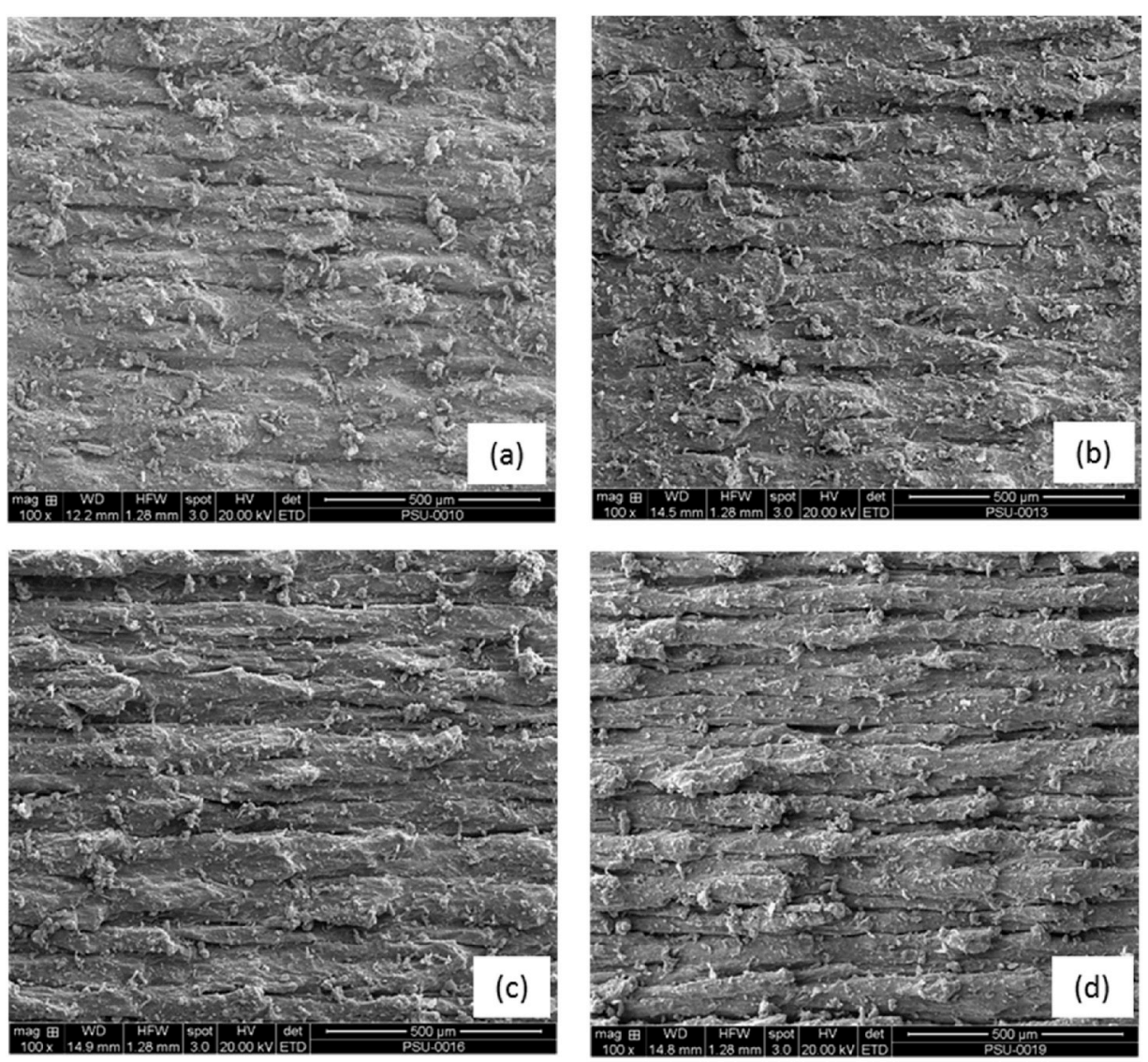

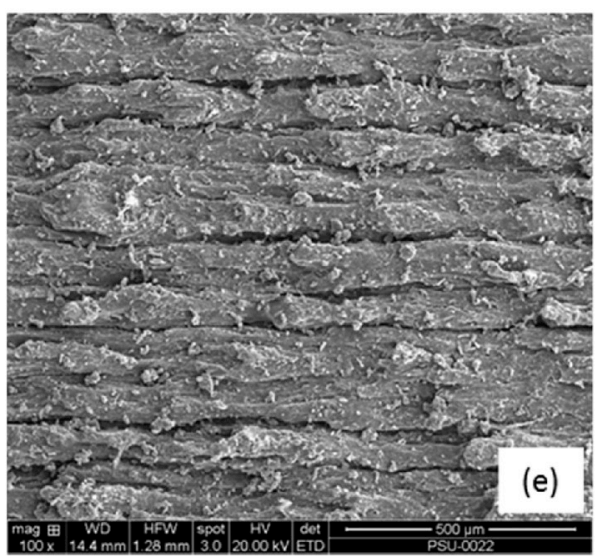

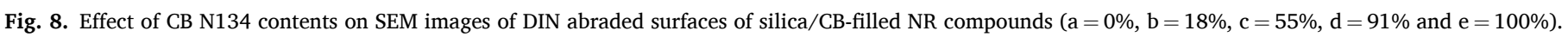



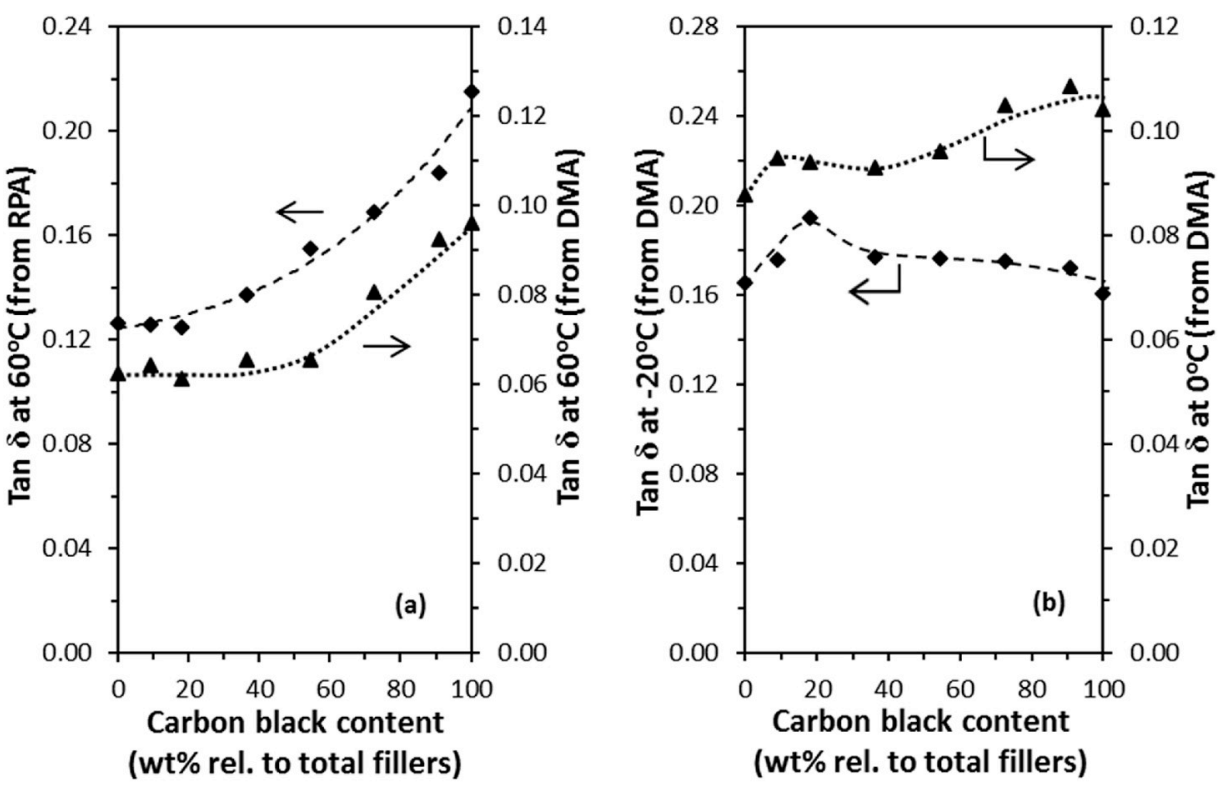

Fig. 9. Effect of $\mathrm{CB} N 134$ contents on tan delta at $60^{\circ} \mathrm{C}$ (a) and tan delta at $-20^{\circ} \mathrm{C}$ and $0{ }^{\circ} \mathrm{C}$ (b) of silica/CB-filled NR compounds.

surface area becomes larger and heat build-up as well as hysteresis of the rubber compound become greater. So, increasing of the $\mathrm{CB}$ proportion in the silica-filled NR compounds too much has a negative effect on tire rolling resistance. Moreover, as well known for the CB-reinforced rubber compounds, the adherence of rubber molecules on to the $\mathrm{CB}$ surface is mainly taking place in the form of physical adsorption, i.e. mainly physical interactions between $\mathrm{CB}$ and rubber. This is different from the case of silica/silane system wherein chemical bonds are created between silica and rubber. Under dynamic deformation conditions when rubber molecules with only physical interactions are detached and reattached to the filler surface, the compounds with more of these physical interactions create higher energy losses and thus higher tan delta at $60^{\circ} \mathrm{C}$.

The increase of $\mathrm{CB}$ ratio in the silica/CB hybrid fillers increases the tan delta at $0{ }^{\circ} \mathrm{C}$ continuously, but rises the tan delta at $-20^{\circ} \mathrm{C}$ to the optimum at $\mathrm{CB}$ loading of $18 \mathrm{wt} \%$ relative to total filler content, thereafter the values decrease slightly. So, with regard to wet grip, the increasing content of $\mathrm{CB}$ gives a positive effect, whereas for ice traction at $-20^{\circ} \mathrm{C}$ the ratio of silica/CB needs some optimization. As observed also for other properties earlier, the use of $\mathrm{CB}$ N134 at $18 \mathrm{wt} \%$ relative to total filler content shows optimum properties which indicate the best balance of both physical and chemical interactions as reflected in the optimum bound rubber contents (Fig. 5 (a)), flocculation rate constant (Fig. 5(b)), tensile strength and elongation at break (Fig. 6(b)) and tear strength (Fig. 7(a)).

\section{Conclusions}

The properties of silica/CB-filled NR compounds show a clear synergistic effect in dependence of the $\mathrm{CB}$ proportion in the hybrid fillers. An increasing ratio of $\mathrm{CB}$ in the compounds steadily increases the viscosities both during and after mixing, mixing temperature, cure rate index, 300\%modulus and DIN abrasion index. The Payne effect and tan delta at $0{ }^{\circ} \mathrm{C}$ and $60^{\circ} \mathrm{C}$ are marginally changed at low content of $\mathrm{CB}$, i.e. in the range of $0-36 \mathrm{wt} \%$ of CB relative to total filler content or $0-20$ phr, but later clearly increase. Scorch and cure times are shortened enabling an increase in productivity and energy saving. Bound rubber content, flocculation rate constant, tensile strength, elongation at break, tear strength and tan delta at $-20^{\circ} \mathrm{C}$ show an optimum at $18 \mathrm{wt} \%$ of $\mathrm{CB}$ relative to total filler content or at the ratio of silica/CB 45/10 phr. Summarizing from the perspective of tire performance, at optimum silica/CB ratio of $18 \mathrm{wt} \%$, the abrasion resistance, wet grip and ice traction can be enhanced while maintaining the tire rolling resistance as indicated by the data from dynamic mechanical analysis.

\section{Data availability}

The raw/processed data required to reproduce these findings cannot be shared at this time as the data also forms part of an ongoing study.

\section{Acknowledgements}

The authors gratefully acknowledge the Dutch Natural Rubber Foundation (Rubber Stichting, the Netherlands), Apollo Tyres Global R\&D B.V. (the Netherlands), and Prince of Songkla University (Thailand) Ph.D. Scholarship for financial support.

\section{Appendix A. Supplementary data}

Supplementary data to this article can be found online at https://doi. org/10.1016/j.polymertesting.2019.106173.

\section{References}

[1] J.W. ten Brinke, S.C. Debnath, L.A.E.M. Reuvekamp, J.W.M. Noordermeer, Mechanistic aspects of the role of coupling agents in silica-rubber composites, Compos. Sci. Technol. 63 (2003), https://doi.org/10.1016/S0266-3538(03)000770.

[2] R. Zafarmehrabian, S.T. Gangali, M.H.R. Ghoreishy, M. Davallu, The effects of silica/carbon black ratio on the dynamic properties of the tread compounds in truck tires, E-J. Chem. 9 (2012), https://doi.org/10.1155/2012/571957.

[3] R. Rauline, Rubber compound and tires based on such a compound, E.P. Pat 0501227A1 (Feb. 2. 1992).

[4] H.D. Luginsland, W. Niedermeier, New Reinforcing Materials for Rising Tire Performance Demands, Rubber World, 222003.

[5] J.T. Byer, M.P. Wagner, Fillers, in: M. Morton (Ed.), Rubber Technology, Springer Science+Business Media, Dordrecht, the Netherlands, 1999, p. 97, https://doi.org/ 10.1007/978-94-017-2925-3.

[6] U. Goerl, A. Hunsche, A. Mueller, H.G. Koban, Investigations into the silica/silane reaction system, Rubber Chem. Technol. 70 (1997), https://doi.org/10.5254/ 1.3538447.

[7] W. Kaewsakul, K. Sahakaro, W.K. Dierkes, J.W.M. Noordermeer, Optimization of mixing conditions for silica-reinforced natural rubber tire tread compounds, Rubber Chem. Technol. 85 (2012), https://doi.org/10.5254/rct.12.88935.

[8] L.A.E.M. Reuvekamp, J.W. ten Brinke, P.J. van Swaaij, J.W.M. Noordermeer, Effects of mixing conditions-reaction of TESPT silane coupling agent during mixing with silica filler and tire rubber, Kautsch. Gummi Kunstst. 55 (2002).

[9] C. Hayichelaeh, L.A.E.M. Reuvekamp, W.K. Dierkes, A. Blume, J.W. M. Noordermeer, K. Sahakaro, Reinforcement of natural rubber by silica/silane in 
dependence of different amines, Rubber Chem. Technol. 90 (2017), https://doi. org/10.5254/rct.82.83708.

[10] C. Hayichelaeh, L.A.E.M. Reuvekamp, W.K. Dierkes, A. Blume, J.W. M. Noordermeer, K. Sahakaro, Promoting interfacial compatibility of silicareinforced natural rubber tire compounds by aliphatic amine, Rubber Chem. Technol. 91 (2018), https://doi.org/10.5254/rct.18.81630.

[11] M. Maiti, M. Bhattacharya, A.K. Bhowmick, Elastomer nanocomposites, Rubber Chem. Technol. 81 (2008), https://doi.org/10.5254/1.3548215.

[12] K. Sahakaro, Mechanism of reinforcement using nanofillers in rubber nanocomposites, in: Progress in Rubber Nanocomposites, Woodhead Publishing, Oxford, UK, 2016, https://doi.org/10.1016/B978-0-08-100409-8.00003-6.

[13] O.J. Ogbebor, A.S. Farid, U.N. Okwu, Properties of silica/clay filled heavy-duty truck tire tread formulation, J. Appl. Polym. Sci. 94 (2004), https://doi.org/ 10.1002/app.20921.

[14] N.I. Nik Ismail, A. Ansarifar, M. Song, Effect of hybrid reinforcement based on precipitated silica and montmorillonite nanofillers on the mechanical properties of a silicone rubber, Polym. Eng. Sci. 54 (2014), https://doi.org/10.1002/pen.23734.

[15] Z. Bao, J. Tao, C. Flanigan, The combination of montmorillonite and silica in styrene-butadiene rubber/polybutadiene rubber tread compounds, Polym. Compos. 38 (2017), https://doi.org/10.1002/pc.23653.

[16] V.R. Vijay, A.M. Anitha, A.R. Menon, Studies on blends of natural rubber and butadiene rubber containing silica-Organomodified kaolin hybrid filler systems, Polymer 89 (2016), https://doi.org/10.1016/j.polymer.2016.02.037.

[17] M. Galimberti, V. Cipolletti, S. Cioppa, A. Lostritto, L. Conzatti, Reduction of filler networking in silica based elastomeric nanocomposites with exfoliated organomontmorillonite, Appl. Clay Sci. 135 (2017), https://doi.org/10.1016/j. clay.2016.09.017.

[18] S. Wolff, E.H. Tan, Paper no.66 Presented at a Meeting of the Rubber Division, American Chemical Society, New York, 1986, pp. 8-11. April.

[19] S.S. Choi, Influence of polymer-filler interactions on retraction behaviors of natural rubber vulcanizates reinforced with silica and carbon black, J. Appl. Polym. Sci. 99 (2006), https://doi.org/10.1002/app.22562.

[20] N. Rattanasom, T. Saowapark, C. Deeprasertkul, Reinforcement of natural rubber with silica/carbon black hybrid filler, Polym. Test. 26 (2007), https://doi.org/ 10.1016/j.polymertesting.2006.12.003.

[21] W. Feng, Z. Tang, P. Weng, B. Guo, Correlation of filler networking with reinforcement and dynamic properties of SSBR/carbon black/silica composites, Rubber Chem. Technol. 88 (2015), https://doi.org/10.5254/rct.15.84881.

[22] K. Senthilvel, S. Vishvanathperumal, B. Prabu, J.L. Baruch, Studies on the morphology, cure characteristics and mechanical properties of acrylonitrile butadiene rubber with hybrid filler (carbon black/silica) composite, Polym. Polym. Compos. 24 (2016), https://doi.org/10.1177/096739111602400705.

[23] S. Sattayanurak, J.W.M. Noordermeer, K. Sahakaro, W. Kaewsakul, W.K. Dierkes, A. Blume, Silica-reinforced natural rubber: synergistic effects by addition of small amounts of secondary fillers to silica-reinforced natural rubber tire tread compounds, Advances in Mat. Sci. and Eng. (2019), https://doi.org/10.1155/ 2019/5891051.

[24] L. Guy, S. Daudey, P. Cochet, Y. Bomal, New insights in the dynamic properties of precipitated silica filled rubber using a new high surface silica, Kautsch. Gummi Kunstst. 62 (2009).

[25] G. Huber, T.A. Vilgis, On the mechanism of hydrodynamic reinforcement in elastic composites, Macromolecules 35 (2002), https://doi.org/10.1021/ma0208887.

[26] G.G.A. Bohm, M.N. Nguyen, Flocculation of carbon black in filled rubber. I. Flocculation occurring in unvulcanized compounds during annealing at elevated temperature, J. Appl. Polym. Sci. 55 (1995), https://doi.org/10.1002/ app.1995.070550707.
[27] C.J. Lin, W.L. Hergenrother, E. Alexanian, G.G.A. Böhm, On the filler flocculation in silica-filled rubbers Part I. Quantifying and tracking the filler flocculation and polymer-filler interactions in the unvulcanized rubber compounds, Rubber Chem. Technol. 75 (2002), https://doi.org/10.5254/1.3547689.

[28] S. Mihara, R.N. Datta, J.W.M. Noordermeer, Flocculation in silica reinforced rubber compounds, Rubber Chem. Technol. 82 (2009), https://doi.org/10.5254/ 1.3548262 .

[29] A. Blume, F. Thibault-Starzyk, Deciphering the silica/silane reaction mechanism for the development of a new generation of low rolling resistance tires: Part 1Characterization by in situ IR spectroscopy, Rubber Fibres Plast. Int. 12 (2017).

[30] B. Dong, C. Liu, Y.P. Wu, Fracture and fatigue of silica/carbon black/natural rubber composites, Polym. Test. 38 (2014), https://doi.org/10.1016/j. polymertesting.2014.06.004

[31] H. Ismail, M. Mathialagan, Comparative study on the effect of partial replacement of silica or calcium carbonate by bentonite on the properties of EPDM composites, Polym. Test. 31 (2012), https://doi.org/10.1016/j.polymertesting.2011.09.002.

[32] F. Enríquez, J.F. Fernández, M.A. de la Rubia, Highly conductive coatings of carbon black/silica composites obtained by a sol-gel process, Carbon 50 (2012), https:// doi.org/10.1016/j.carbon.2012.05.019.

[33] J. Wang, Q. Li, C. Wu, H. Xu, Thermal conductivity and mechanical properties of carbon black filled silicone rubber, Polym. Polym. Compos. 22 (2014), https://doi. org/10.1177/096739111402200405.

[34] A.R. Payne, Effect of dispersion on dynamic properties of filler-loaded rubbers, Rubber Chem. Technol. 39 (1966), https://doi.org/10.1002/ app.1965.070090619.

[35] S. Wolff, M.J. Wang, E.H. Tan, Filler-elastomer interactions. Part VII. Study on bound rubber, Rubber Chem. Technol. 66 (1993), https://doi.org/10.5254/ 1.3538304 .

[36] S.S. Choi, Influence of storage time and temperature and silane coupling agent on bound rubber formation in filled styrene-butadiene rubber compounds, Polym. Test. 21 (2002), https://doi.org/10.1016/S0142-9418(01)00071-X.

[37] S.S. Choi, E. Ko, Novel test method to estimate bound rubber formation of silicafilled solution styrene-butadiene rubber compounds, Polym. Test. 40 (2014), https://doi.org/10.1016/j.polymertesting.2014.09.003.

[38] J.G. Meier, M. Klüppel, Carbon black networking in elastomers monitored by dynamic mechanical and dielectric spectroscopy, Macromol. Mater. Eng. 293 (2008), https://doi.org/10.1002/mame.200700228.

[39] L.B. Tunnicliffe, J. Kadlcak, M.D. Morris, Y. Shi, A.G. Thomas, J.J.C. Busfield, Flocculation and viscoelastic behaviour in carbon black-filled natural rubber, Macromol. Mater. Eng. 299 (2014), https://doi.org/10.1002/mame.201400117.

[40] Y. Fukahori, New progress in the theory and model of carbon black reinforcement of elastomers, J. Appl. Polym. Sci. 95 (2005), https://doi.org/10.1002/app.20802.

[41] A.H. Muhr, A.D. Roberts, Rubber abrasion and wear, Wear 158 (1992), https://doi. org/10.1016/0043-1648(92)90040-F.

[42] A. Schallamach, Friction and abrasion of rubber, Wear 1 (1958), https://doi.org/ 10.1016/0043-1648(58)90113-3.

[43] H. Liang, Y. Fukahori, A.G. Thomas, J.J.C. Busfield, The steady state abrasion of rubber: why are the weakest rubber compounds so good in abrasion? Wear 268 (2010) https://doi.org/10.1016/j.wear.2009.11.015.

[44] Y. Fukahori, H. Yamazaki, Mechanism of rubber abrasion. Part I: abrasion pattern formation in natural rubber vulcanizate, Wear 171 (1994), https://doi.org/ 10.1016/0043-1648(94)90362-X.

[45] K.H. Nordsiek, The "integral rubber" concept - an approach to an ideal tire tread rubber, Kautsch. Gummi Kunstst. 38 (1985). 